Назаров Александр Алексеевич

старший преподаватель кафедры

бухгалтерского учета и электронного бизнеса

Чувашского государственного университета

имени И.Н. Ульянова

\section{ХАРАКТЕРИСТИКА СОВРЕМЕННЫХ ИНСТРУМЕНТОВ ДЛЯ ИМИТАЦИОННОГО МОДЕЛИРОВАНИЯ \\ ПРИ ИССЛЕДОВАНИИ \\ МЕХАНИЗМОВ УПРАВЛЕНИЯ \\ СОЦИАЛЬНО-ЭКОНОМИЧЕСКИМИ ПРОЦЕССАМИ И СИСТЕМАМИ [1]}

Аннотация:

В статье представлен обзор прикладного программного обеспечения и интегрированных систем программирования, призванных существенно облегчить моделирование социальноэкономических систем, проведение экспериментов и выведение результатов в виде как таблии, так и визуальных интерпретаций.

Ключевые слова:

имитационное моделирование, системная динамика, агент-ориентированное моделирование, дискретно-событийное моделирование, управление социально-экономическими системами, программное обеспечение для имитационного моделирования, вычислимые модели, прогнозирование.
Nazarov Alexander Alekseyevich

Senior Lecturer, Accounting and E-business Department, Chuvash State University

\section{DESCRIPTION OF MODERN TOOLS OF SIMULATION MODELING WHEN STUDYING THE MECHANISMS OF SOCIO-ECONOMIC SYSTEMS AND PROCESSES MANAGEMENT [1]}

Summary:

The article presents an overview of applied software and integrated software engineering systems designed to simplify considerably the process of modeling of socio-economic systems, experimentation and display of the results in both tabular form and visual interpretation one.

Keywords: simulation modeling, system dynamics, agent-based modeling, discrete event simulation, management of social and economic systems, simulation software, computable model, prediction.

Благодаря интенсивному и широкому развитию информационных технологий, связанных с развитием высокопроизводительных компьютерных систем, стало намного проще решать задачи, требующие огромных временных и фринансовых ресурсов. Особенно это касается сфер, в которых натурные эксперименты невозможны в силу нарушения фундаментальных принципов проведения научных экспериментов (с точки зрения воспроизведения всех условий среды). Также следует отметить, что аналитическое решение математических моделей и само их построение, включающее обратные связи, нелинейность, недостаток числа уравнений в системе для получения однозначного решения и даже рекурсивность формул в рамках одной системы, делают этот процесс непригодным для выработки адекватных выводов по реальным микро- и макроэкономическим системам [2].

Тем не менее в подобных ситуациях не требуются фундаментальные выводы по всему классу изучаемых моделей. Достаточно и конкретного численного эксперимента, чтобы судить о возможности или невозможности практической реализации идеи либо об оптимальности или неоптимальности функционирования существующей системы, а также предположений и определенных направлений для повышения эффективности системы в рамках ограничений в ресурсах. Такие численное решение и визуальное представление результатов могут дать модели, формируемые по принципам и методам имитационного моделирования [3].

В данной статье представлен обзор прикладного программного обеспечения и интегрированных систем программирования, призванных существенно облегчить построение модели, проведение экспериментов и выведение результатов как в табличном виде, так и в виде визуальных моделей. Условно программное обеспечение для имитационного моделирования социально-экономических систем можно разбить на следующие четыре группы.

1. К первой относятся интегрированные программные среды и отдельные универсальные языки программирования высокого уровня (Pascal, Basic, C, C++ и др.). В этом случае строится алгоритмическая модель решаемой задачи, описывается либо в качественном виде, либо в виде блок-схемы, далее алгоритм кодируется при помощи стандартного синтаксиса выбранного языка программирования. 
2. Ко второй группе относится программное обеспечение с применением специализированных языков моделирования (GPSS, SIMULA, SIMSCRIPT, CSL, SOL, GASP, SLAM и др.), написанных на универсальных языках. В данных программных инструментах для имитационного моделирования реализованы способы взаимодействия и динамика системы через отношения составных элементов во времени и пространстве. Данная группа языков требует от пользователя знаний и подготовки в области имитационного моделирования, чтобы описать механизмы организации модели в терминах выбранного языка. Программное обеспечение имеет обширный круг практического приложения, само программное обеспечение компактно и нетребовательно к вычислительным ресурсам ЭВМ.

3. К третьей группе относятся специализированные программные среды с включением всего цикла создания имитационной модели от разработки визуальной схемы функционирования до визуального вывода процесса и результатов моделирования (Arena, AnyLogic, GPSS World, VisSim). При этом программная среда менее требовательна к знаниям пользователя в области программирования и управление имитационной моделью осуществляется через специальные формы. В таких средах реализован удобный интерфейс ввода управляющих параметров для проведения экспериментов и получения оптимального значения целевых критериев.

4. К четвертой группе программного обеспечения относятся стандартные специализированные математические среды с включением пакета имитационного моделирования (пакет Simulink системы Matlab, Mathcad, Mathematica, SPSS, Statistica). В данном программном обеспечении инструмент имитационного моделирования рассматривается как отдельная надстройка и поставляется в виде инсталляционного пакета как расширение стандартных функций. Как и стандартные математические пакеты, подобная надстройка предоставляет возможность ввода, вывода и расчета функций, построения графиков и др.

В таблице 1 рассмотрены основные существующие на данный момент интегрированные программные системы для имитационного моделирования AnyLogic, Arena, Simulink.

\begin{tabular}{|c|c|c|c|}
\hline \multirow{2}{*}{ Характеристика } & \multicolumn{3}{|c|}{ Система } \\
\hline & AnyLogic 7.3 & Simulink 9.1 & Arena 15.0 \\
\hline Продукт & $\begin{array}{l}\text { Инструмент имитационного } \\
\text { моделирования, который } \\
\text { поддерживает все подходы } \\
\text { к созданию имитационных } \\
\text { моделей: дискретно-собы- } \\
\text { тийный, системно-динами- } \\
\text { ческий и агентный. Гиб- } \\
\text { кость и мощность языка мо- } \\
\text { делирования АnуLоgіс поз- } \\
\text { воляют учесть каждый ас- } \\
\text { пект моделируемой си- } \\
\text { стемы с любым уровнем де-- } \\
\text { тализации. Графичческий } \\
\text { интерфейс АпуLоgіс, ин- } \\
\text { струменты и библиотеки } \\
\text { дают возможность быстро } \\
\text { реализовывать модели для } \\
\text { широкого спектра задач от } \\
\text { моделирования производ- } \\
\text { ства, логистики, бизнес- } \\
\text { процессов до стратегиче- } \\
\text { ских моделей развития ком- } \\
\text { пании и рынков [4] }\end{array}$ & $\begin{array}{l}\text { Графиическая среда ими- } \\
\text { тационного моделирова- } \\
\text { ния, позволяющая при по- } \\
\text { мощи блок-диаграмм в } \\
\text { виде направленных гра- } \\
\text { фов строить динамиче- } \\
\text { ские модели, включая } \\
\text { дискретные, непрерыв- } \\
\text { ные, гибрридные, нелиней- } \\
\text { ные и разрывные си- } \\
\text { стемы. Интерактивная } \\
\text { среда Simulink дает воз- } \\
\text { можность использовать } \\
\text { готовые библиотеки бло- } \\
\text { ков для моделирования } \\
\text { электросиловых, механи- } \\
\text { ческих и гидравлических } \\
\text { систем, а также приме- } \\
\text { нять развитый модельно- } \\
\text { ориентированный подход } \\
\text { при разработке систем } \\
\text { управления, средств цифр- } \\
\text { ровой связи и устройств } \\
\text { реального времени [5] }\end{array}$ & $\begin{array}{l}\text { Является интегрирован- } \\
\text { ной программной средой } \\
\text { для дискретно-событий- } \\
\text { ного моделирования и по- } \\
\text { строения бизнес-процес- } \\
\text { сов. } \\
\text { Пользователь может раз- } \\
\text { рабатывать модель путем } \\
\text { размещения модулей (из } \\
\text { библиотеки), которые } \\
\text { представляют собой про- } \\
\text { цессы или логику. Готовые } \\
\text { модули интерпретируются } \\
\text { как реальные процессы, } \\
\text { потоки и действия, опре- } \\
\text { деляемые по аналогии са- } \\
\text { мим разработчиком ими- } \\
\text { тационной моели. Реали- } \\
\text { зован удобный интерфрейс } \\
\text { вывода статистических } \\
\text { данных - результата мо- } \\
\text { делирования [6] }\end{array}$ \\
\hline Язык интерфейса & Русский & Английский & Английский \\
\hline $\begin{array}{l}\text { Поддержка } \\
\text { и обучение }\end{array}$ & Да (расширенная) & Да & Да \\
\hline $\begin{array}{l}\text { Визуализация } \\
\text { процесса } \\
\text { моделирования }\end{array}$ & Да & Да & Да \\
\hline $\begin{array}{l}\text { Открытая } \\
\text { архитектура }\end{array}$ & Да & Да & Да \\
\hline Анимация & Да & Да & Да \\
\hline Анализ данных & Да & Да & Да \\
\hline
\end{tabular}


Продолжение таблицы 1

\begin{tabular}{|c|c|c|c|}
\hline \multirow{2}{*}{ Характеристика } & \multicolumn{3}{|c|}{ Система } \\
\hline & AnyLogic 7.3 & Simulink 9.1 & Arena 15.0 \\
\hline $\begin{array}{l}\text { Библиотека } \\
\text { моделей }\end{array}$ & Да (расширенная) & Да & Да \\
\hline $\begin{array}{l}\text { Системные } \\
\text { требования }\end{array}$ & $\begin{array}{l}\text { Microsoft Windows } 10,8,7 \\
\text { SP1, ×86-32 и ×64 } \\
\text { Apple Mac OS X } 10.7 .3 \text { (Lion) } \\
\text { или выше, Universal } \\
\text { SuSE Linux, ×86-32 } \\
\text { Ubuntu Linux 10.04 или } \\
\text { выше, ×86-32 }\end{array}$ & $\begin{array}{l}\text { MATLAB } \\
\text { Simulink требуется для } \\
\text { всех продуктов автомати- } \\
\text { зированного проектиро- } \\
\text { вания и моделирования }\end{array}$ & $\begin{array}{l}\text { Microsoft Windows } 10,8,7 \\
\text { SP1, ×86-32 и ×64 } \\
\text { Apple Mac OS X } 10.7 .3 \\
\text { (Lion) или выше, Universal } \\
\text { SuSE Linux, ×86-32 } \\
\text { Ubuntu Linux } 10.04 \text { или } \\
\text { выше, ×86-32 }\end{array}$ \\
\hline $\begin{array}{l}\text { Аппаратные } \\
\text { требования }\end{array}$ & $\begin{array}{l}500 \text { Мб свободного диско- } \\
\text { вого пространства } \\
2 \text { Гб памяти }\end{array}$ & $\begin{array}{l}500 \text { Мб свободного диско- } \\
\text { вого пространства } \\
2 \text { Гб памяти }\end{array}$ & $\begin{array}{l}500 \text { Мб свободного диско- } \\
\text { вого пространства } \\
2 \text { Гб памяти }\end{array}$ \\
\hline
\end{tabular}

Описанные специализированные интегрированные системы для имитационного моделирования обладают достаточной функциональностью и высокой эффективностью при разработке имитационных моделей реальных и гипотетических социально-экономических систем. На современном этапе развития имитационного моделирования все большую популярность завоевывают комбинированные способы построения имитационных моделей с точки зрения подходов к построению моделей. Этому условию достаточно полно отвечает интегрированная система AnyLogic, так как в ней реализованы данные механизмы и существует обширная готовая библиотека модулей и разработанных моделей. Конечно, выбор той или иной системы моделирования или инструмента зависит от многих условий. В некоторых случаях удобнее использовать универсальные языки моделирования для более тонкой настройки модели.

\section{Ссылки и примечания:}

1. Исследование выполнено при фринансовой поддержке РГНФ (проект № 16-02-00600а).

2. Никитин В.В., Бобин Д.В., Назаров А.А. Моделирование интегрального показателя комплексной оценки объектов исследования // Вестник Чувашского университета. 2015. № 3. С. 172-177.

3. Nikitin V.V., Krasnov A.S., Nazarov A.A. Comparative estimation of Russia's regions investment potential on the base of the multivariate statistical analysis // European researcher. Series A. 2013. No. 1-1 (38). P. 20-27.

4. Почемy AnyLogic? [Электронный ресурc]. URL: http://www.anylogic.ru/features (дата обращения: 20.12.2016).

5. Simulink [Электронный ресурc]. URL: http://matlab.ru/products/simulink (дата обращения: 20.12.2016).

6. Discrete Event Simulation Software [Электронный ресурc]. URL: https://www.arenasimulation.com (дата обращения: 20.12.2016)

\section{References:}

Discrete Event Simulation Software 2016, viewed 20 December 2016, <https://www.arenasimulation.com>.

Nikitin, VV, Bobin, DV \& Nazarov, AA 2015, 'Integral index modeling of complex evaluation of research objects', Vestnik Chuvashskogo universiteta, no. 3, pp. 172-177, (in Russian).

Nikitin, VV, Krasnov, AS \& Nazarov, AA 2013, 'Comparative estimation of Russia's regions, investment potential on the base of the multivariate statistical analysis', European researcher, Series A. No. 1-1 (38), pp. 20-27.

Simulink 2016, viewed 20 December 2016, <http://matlab.ru/products/simulink>, (in Russian).

Why AnyLogic? 2016, viewed 20 December 2016, <http://www.anylogic.ru/features>, (in Russian). 